O. Gentilhomme, et al., Int. J. of Safety and Security Eng., Vol. 6 No. 2 (2016) 219-228

\title{
FOLD PROJECT: EXPERIMENTAL ASSESSMENT OF THE EFFICIENCY OF AN OPTICAL FIBRE TO DETECT A GASEOUS LEAK IN A BURIED PIPE
}

\author{
O. GENTILHOMME ${ }^{1}$, G. AUDOUIN ${ }^{2}$, D. HOUSSIN ${ }^{3}$, B. RAGUIN ${ }^{4} \&$ J-P LEININGER $^{5}$ \\ ${ }^{1}$ INERIS, France. \\ ${ }^{2}$ TOTAL, France. \\ ${ }^{3}$ AIR LIQUIDE, France. \\ ${ }^{4}$ GRTgaz, France. \\ ${ }^{5}$ ENGIE E\&P International, France.
}

\begin{abstract}
In 2015, TOTAL, AIR LIQUIDE, GRTgaz, ENGIE E\&P International and INERIS were involved in a collaborative project called FOLD. The objective of this project was to experimentally assess the capability of an optical fibre based system to detect gaseous leaks occurring in a buried pipe. During this project, several parameters were tested in relation to the release properties (nature of gas, orifice diameter, pressure, direction etc.), to the installation of the optical cable (offset location from the pipe, protection around the cable) and to the scanning means (interrogation distance, interrogator technology). This article presents the experimental bench that was used during the testing campaign and some of the results obtained with the DTS (Distributed Temperature Sensing) equipment when this was interrogating the optical cable on short distances (less than $500 \mathrm{~m}$ ). By analysing these results, it is already possible to give recommendations regarding the best positioning of the optical cable along the buried pipe to optimise the efficiency of the optical fibre based detection system.
\end{abstract}

Keywords: detection, fibre optic, leak, gas transportation pipeline.

\section{INTRODUCTION}

According to EGIG [1], Western Europe is crossed by a network of gas transport pipeline as long as $145000 \mathrm{~km}$. Most of these pipelines, with the exception of some components that are necessary for exploitation (compressor/pump stations, block valve stations...), are buried. Approximately 20 incidents of gaseous leaks are reported each year on this network. From 2004 to 2013,35\% of these incidents were caused by external aggressions (external work), $24 \%$ by corrosion and $16 \%$ by material weakness. The origin of other incidents is unknown. Over the past few years, the number of incidents has been decreasing but the percentage caused by corrosion is growing. The installation becomes more vulnerable to natural aggression as it gets older.

There exists different means to detect a gaseous leak occurring on a buried pipeline. So-called 'internally based methodologies' (using pressure or flowrate transducers placed at both ends of the pipe) can be adapted when targeting important leaks such as one arising from the full-bore rupture of a pipe. Yet these internal methodologies might prove inefficient for a small leak induced, for instance, by corrosion. To make sure that detection will occur no matter how small the leak flow rate is, it could be interesting to use both internal and external detection means. Among the different technologies available for external sensing (acoustic 
emission detectors, sensing cable etc.), the optical fibre seems to be a promising candidate. However, there is currently neither an established procedure for positioning the optical fibre around the pipe (Above or under the pipe? How far away?) nor any quantification of the detection limits of such systems.

In 2015, TOTAL, AIR LIQUIDE, GRTgaz, ENGIE E\&P International and INERIS were involved in a project called FOLD (Fibre Optical Leak Detection). The objective of this project was to experimentally assess the capability of two technologies of optical fibre interrogators (DTS - Distributed Temperature Sensing \& DAS - Distributed Acoustic Sensing) to detect even a small gaseous leak on a buried pipe.

\section{DESCRIPTION OF THE EXPERIMENTAL BENCH}

\subsection{Leak simulating pipe}

All leaks were simulated from the external surface of a steel pipe that was identical to those used for gas transportation. This pipe, whose original coal tar enamel coating was removed, was $30 \mathrm{~m}$ long and had an internal diameter of $390 \mathrm{~mm}$. This pipe was not filled with pressurised gas but was rather used as a simple cylindrical envelope aimed at housing all lines required to feed the leaks. Its presence also ensured that the behaviour of the gas, once released into the soil, would be similar that in a real hazardous situation.

As can be seen from Fig. 1, there were 12 nozzle orifices on the pipe enabling the investigation of 4 different leak diameters (1,3,5 and $7 \mathrm{~mm}$ ) and 3 different leak directions (upwards, sideways and downwards). The first and last rows of nozzle orifices were located $5 \mathrm{~m}$ from both ends of the pipe. The rows were equally distributed along the remaining length.

Each nozzle orifice was connected to its own gas feeding line (see Fig. 2). These lines were made of stainless steel and had a nominal size of 1 inch. This dimension was chosen so that the surface area of the biggest orifice was much lower than that of the cross sectional area of the line thereby ensuring that the pressure losses would occur in the vicinity of the orifice and not (or very little) along the line. Care was also taken not to impose sharp bends to the lines. The nozzle orifice was flush-mounted with the external surface of the pipe. Just upstream of the orifice, there was a non-fragmenting bursting disc. When closed, it prevented the soil from being ingested into the gas line. In addition, it is assumed that the noise resulting from bursting would be similar to the one generated by a sudden crack on a faulty pipeline. The disc was of non-fragmenting type to prevent the orifice being clogged after bursting.

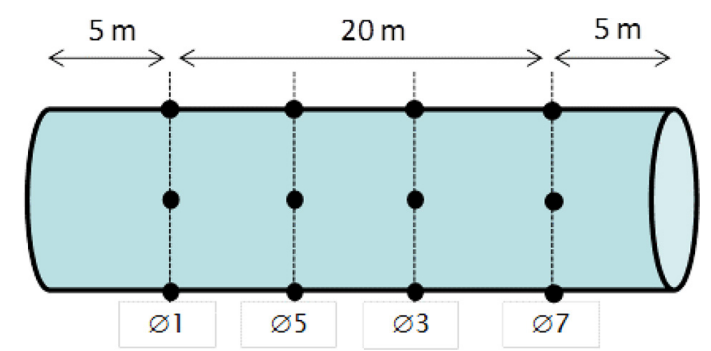

Figure 1: Location of the nozzle orifices on the pipe. 

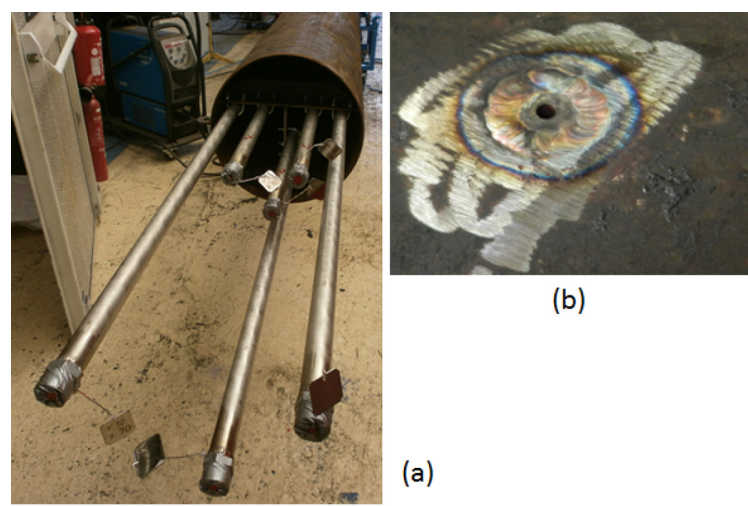

(b)

Figure 2: Picture of the feeding lines (a) and of one nozzle orifice (b).
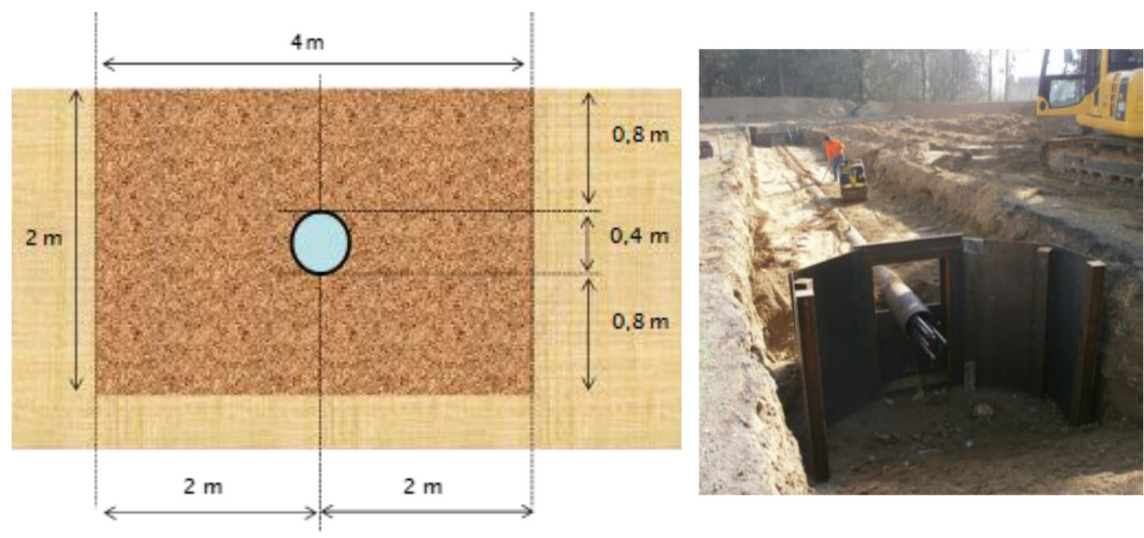

Figure 3: Burying of the pipe.

As illustrated in Fig. 3, the assembly made up by the pipe and the gas feeding lines was buried at mid-depth in a trench with overall dimensions: $1 \times \mathrm{L} \times \mathrm{H}=4 \mathrm{~m} \times 30,0 \mathrm{~m} \times 2,0 \mathrm{~m}$. This trench was then filled again with the excavated granular-type soil at a known level of compaction. It is worth pointing out that there was no plastic sheet to delimit the trench. Thus, the leaking gas was free to migrate from the compacted soil to the surrounding one.

\subsection{Optical fibre based detection system}

\subsubsection{Operating principle}

Basically, the system makes use of a nonlinear interaction between an optical signal and the glass material of which the fibre is made. If a pulse of light of known wavelength is launched into a fibre, a very small amount of the power is scattered back at several points along the fibre. This back-scattered light contains components at wavelengths that are identical from the original signal (Rayleigh) or different (Raman and Brillouin). They contain information on the local properties of the fibre such as its deformation that may be caused by acoustic waves (Rayleigh), its tension (Brillouin) and its experienced temperature (Raman and Brillouin). 


\subsubsection{Main components}

The detection system that was used during the FOLD project can be divided into three main components:

- An interrogator in charge of sending the incident light and retrieving the physical data from the scattered light. Table 1 lists all the tested apparatus. Four of them were based on DTS and the last one on DAS. It should be pointed out that all settings were freely made by the suppliers prior to the experimental campaign (with the sole exception of Supplier $\mathrm{n}^{\circ} 3$ who changed the sampling resolution at the beginning).

- An optical cable acts as a light transmitter. This cable was typical of those that were installed near gas pipelines. It was about $500 \mathrm{~m}$ long and contained a total of 12 fibres, including 8 single-mode fibres (G652 9/125 $\mu \mathrm{m}$ ) and 4 multi-mode fibres (G651 50/125 $\mu \mathrm{m}$ ). Each tested interrogator was connected to its own requested fibre(s). As highlighted by Fig. 4, the optical cable first circulated in open air from the testing room where all interrogators were sited to the test bench. Then, this cable made a total of 9 passes all along the buried pipe. Most of them were located above the pipe. Between two consecutive passes, an approximate 8-m semi-circular aerial loop was made with the cable.

* Passes A, B and C correspond to probable locations of an optical cable deployed in retrofit on already installed pipelines not equipped with a telecom fibre optic cable.

* Passes $\mathrm{F}$ and $\mathrm{G}$ were almost identical except that the second one was pulled through a polyethylene tubing of internal and external diameters equal to 32,6 and 40,0 mm, respectively. Comparison of the results for these two particular passes, made it possible to check whether the use of such protection would reduce, or even inhibit, the capability of the detection system.

* Pass H was installed very close to the pipe. It was not clamped or glued to the pipe but simply rested on it.

Table 1: Main features of the tested apparatus (DTS: Distributed Temperature Sensing, DAS: Distributed Acoustic Sensing, SPR: Spatial resolution, SAR: Sampling resolution, MT: measurement time).

\begin{tabular}{|c|c|c|c|c|}
\hline $\begin{array}{l}\text { Equip. } \\
n^{\circ}\end{array}$ & $\begin{array}{c}\text { Supplier } \\
\mathbf{n}^{\circ}\end{array}$ & $\begin{array}{c}\text { Sensing } \\
\text { mean }\end{array}$ & $\begin{array}{l}\text { Wavelength of } \\
\text { interest }\end{array}$ & Settings \\
\hline 1 & 1 & & Raman & $\begin{array}{c}\mathrm{SPR}=1,0 \mathrm{~m} \\
\mathrm{SAR}=1,0 \mathrm{~m} \\
\mathrm{MT}=180 \mathrm{~s}\end{array}$ \\
\hline 2 & 1 & & Brillouin & $\begin{array}{l}\mathrm{SPR}=1,5 \mathrm{~m} \\
\mathrm{SAR}=0,5 \mathrm{~m} \\
\mathrm{MT}=105 \mathrm{~s}\end{array}$ \\
\hline 3 & 2 & DTS & Brillouin & $\begin{array}{c}\mathrm{SPR}=1,5 \mathrm{~m} \\
\mathrm{SAR}=0,5 \mathrm{~m} \\
\mathrm{MT}=300 \mathrm{~s}\end{array}$ \\
\hline 4 & 3 & & Raman & $\begin{array}{c}\mathrm{SPR}=1,0 \mathrm{~m} \\
\mathrm{SAR}=1 \mathrm{~m} \text { (before Test 6) } \\
\text { and } 0,5 \mathrm{~m} \text { (after) } \\
\mathrm{MT}=30 \mathrm{~s}\end{array}$ \\
\hline 5 & 4 & DAS & Rayleigh & $\mathrm{SPR}=10,0 \mathrm{~m}$ \\
\hline
\end{tabular}




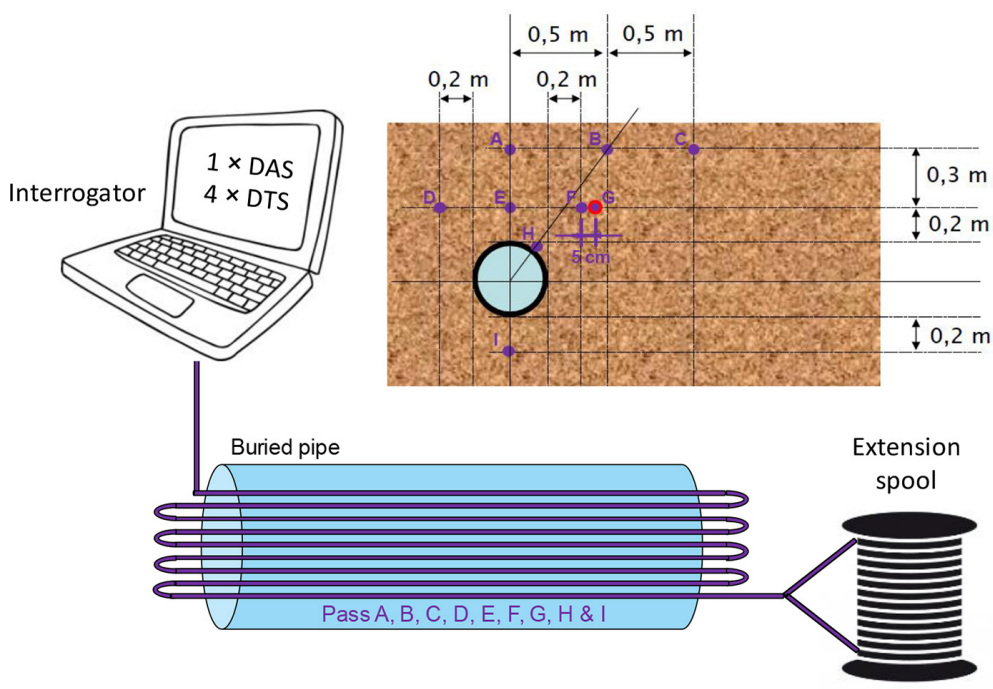

Figure 4: External positioning of the optical cable near the buried pipe.

- An extension spool of approximately $20 \mathrm{~km}$. This component was added to test the detection capability of an optical fibre on short and long distances (respectively $<0,5$ and $>$ $20 \mathrm{~km}$ ). There was one spool for each tested interrogator and this component was simply connected (and not spliced) to the fibres of the optical cable.

\section{TESTING MATRIX}

Table 2 presents the testing matrix. A total of 21 tests were carried out over the rental period of the interrogators (i.e. 5 weeks). Each test lasted 15 min with the exception of Tests $\mathrm{n}^{\circ} 17$ and 21. It is also worth pointing out that the released pressure tended to decrease for Tests $\mathrm{n}^{\circ} 13,14$ and 19. Following Test $\mathrm{n}^{\circ} 14$ that damaged Pass I of the optical cable, the extension spools were connected directly at the exit of Pass $\mathrm{H}$ and Pass I no longer existed.

\section{EXPERIMENTAL RESULTS}

As the data generated by the DAS interrogator are still being analysed, this communication will only focus on the results given by the DTS interrogators. 4 out of the 5 tested sensing devices are, therefore, related to the following discussion.

In addition, this discussion is intentionally narrowed to the behaviour of the sensing device when the optical cable was interrogated over a short distance (up to $500 \mathrm{~m}$ ) and when methane was released within $15 \mathrm{~min}$.

\subsection{Typical results obtained with a DTS interrogator}

Figure 5 shows some of the data obtained with Equipment $n^{\circ} 1$ during Test 4 . Test 4 corresponds to methane being released upward, through a 3-mm orifice, and at a pressure of 77 bar. The leak started at $11 \mathrm{~h} 25 \mathrm{~min} 29 \mathrm{~s}$ and lasted $15 \mathrm{~min}$. The data are presented as the temperature difference between the profile measured at a given instant during the leak and the mean profile measured before the leak. 
Table 2: Testing matrix (AO: bursting disc Already-Opened).

\begin{tabular}{lcccccc}
\hline Test $\mathbf{n}^{\circ}$ & Gas & $\varnothing[\mathbf{m m}]$ & $\mathbf{P}[\mathbf{b a r}]$ & Direction & Duration [min] & Bursting Disc \\
\hline 1 & $\mathrm{CH}_{4}$ & 1 & 81 & $\mathrm{Up}$ & 15 & \\
2 & $\mathrm{CH}_{4}$ & 7 & 48 & Down & 15 & \\
3 & $\mathrm{CH}_{4}$ & 1 & 23 & Up & 15 & AO \\
4 & $\mathrm{CH}_{4}$ & 3 & 77 & Up & 15 & \\
5 & $\mathrm{CH}_{4}$ & 7 & 20 & Down & 15 & AO \\
6 & $\mathrm{CH}_{4}$ & 1 & 111 & Down & 15 & \\
7 & $\mathrm{CH}_{4}$ & 1 & 112 & Side & 15 & \\
8 & $\mathrm{CH}_{4}$ & 7 & 44 & Side & 15 & \\
9 & $\mathrm{CH}_{4}$ & 3 & 79 & Down & 15 & \\
10 & $\mathrm{CH}_{4}$ & 3 & 19 & Down & 15 & AO \\
11 & $\mathrm{CH}_{4}$ & 3 & 87 & Side & 15 & \\
12 & $\mathrm{CH}_{4}$ & 3 & 16 & Side & 15 & AO \\
13 & $\mathrm{CH}_{4}$ & 7 & 77 & Up & 15 & \\
14 & $\mathrm{H}_{2}$ & 5 & 48 & Down & 15 & AO \\
15 & $\mathrm{CH}_{4}$ & 3 & 40 & Up & 15 & AO \\
16 & $\mathrm{CH}_{4}$ & 3 & 39 & Down & 15 & AO \\
17 & $\mathrm{CH}_{4}$ & 3 & 40 & Side & 162 & AO \\
18 & $\mathrm{~N}_{2}$ & 7 & 19 & Down & 15 & AO \\
19 & $\mathrm{CH}_{4}$ & 7 & 18 & Up & 15 & AO \\
20 & $\mathrm{CH}_{4}$ & 1 & 99 & Up & 15 & \\
21 & $\mathrm{H}_{2}$ & 1 & 102 & Up & 138 & \\
\hline
\end{tabular}

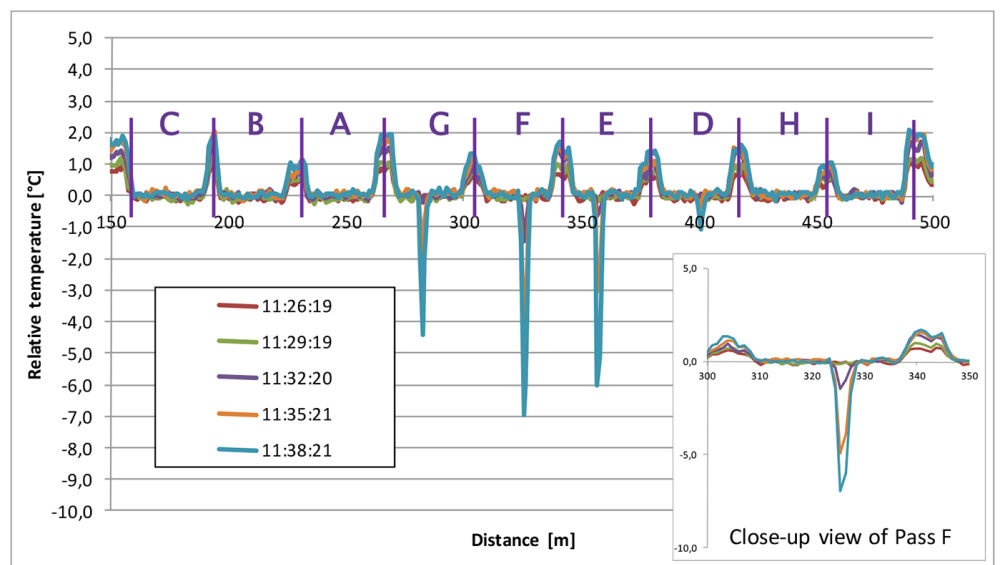

Figure 5: Typical results obtained with Equipment $n^{\circ} 1$ - Test 4.

The behaviour of this equipment was relatively similar to that of the other DTS interrogators. Before the leak, the profile along the cable was far from being homogeneous. Sections of cable were indeed aerial (i.e. the semi-circular loops at each end of the pipe) and thus 
measured the varying ambient air temperature whereas the buried sections (i.e. the 9 passes along the pipe) were relatively steady in temperature. When the leak started, Passes G, F and $\mathrm{E}$ (and to a lesser extent D) measured a temperature drop of several ${ }^{\circ} \mathrm{C}$ and thus succeeded in detecting the cooling effect caused by the Joule-Thomson effect. Interestingly, this was not the case with the other passes.

By comparing the results obtained with Passes F and G, one can also assess the impact of pulling the optical cable through a polyethylene tubing depending on the efficiency of the detection system. For this Test 4, the plastic tubing seemed to reduce the measured cooling by one third but did not seem to inhibit its detection capability.

\subsection{Overall results obtained with the DTS interrogators}

Table 3 presents the success ratio of the DTS interrogators for a given leak and for a given pass of the optical cable along the buried pipe The data in the table should be read as follows: for Test 4, 75\% of the DTS interrogators succeeded in detecting the leak on Pass H. It must be pointed out that results are based on the conclusions provided by the suppliers at the end of the testing campaign. For most of the suppliers, detection relied on first calculating the standard deviation of several consecutive temperature profiles in the absence of leak and then on comparing the temperature drop measured by the interrogator during the leak to this

Table 3: Success ratio of the DTS interrogators for short-distance interrogation based on the conclusions of the different suppliers - Chronological order (NA: Not Available).

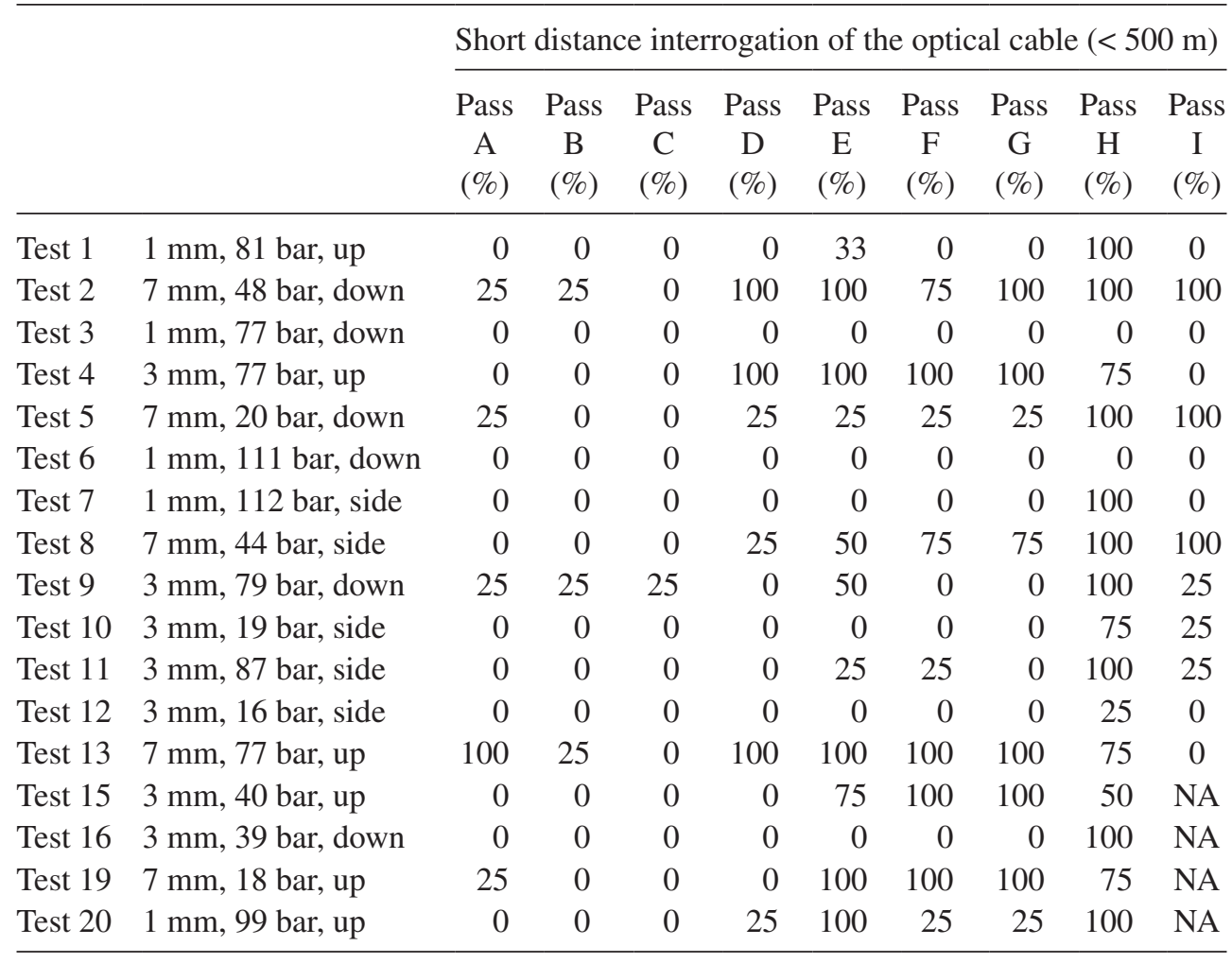


calculated standard deviation. If the temperature drop was 'much' higher, they would conclude on clear detection. If not, the leak would be undetected.

Table 4 shows the same overall results but tests are not ordered in a chronological way, as before, but as a function of $D^{2} \sqrt{ } P$ (where $\mathrm{D}$ is the orifice diameter in $\mathrm{mm}$ and $\mathrm{P}$ the released pressure in bar). This parameter is directly proportional to the released mass flow rate. It is thought that this presentation will facilitate the interpretation of the results. At least, by comparing Tables 3 and 4, it seems to re-arrange in a more convenient way the situations where there was detection.

Based on the results from this table, one can draw the following preliminary conclusions:

- The leaks were rarely detected on Passes A, B and C. For these passes, the optical cable was too far from the buried pipe to be able to detect the simulated gaseous leaks. In addition, by placing it too close to the soil surface, it becomes more vulnerable to external aggressions (e.g. digging operations) and possibly more sensitive to the variation of ambient air temperature which in turn will require imposing less stringent detection thresholds to prevent the activation of too many false alarms thereby reducing the detection efficiency of the optical cable in this area.

- There is hardly any difference between Pass F and Pass G. This confirms what was already observed during the analysis of the date presented in Fig. 5: protecting the optical cable inside a polyethylene tubing does not seem to jeopardize the efficiency of the detection system.

Table 4: Success ratio of the DTS interrogators for short-distance interrogation based on the conclusions of the different suppliers (NA: Not Available).

\begin{tabular}{|c|c|c|c|c|c|c|c|c|c|c|c|}
\hline & & \multirow[b]{2}{*}{$D^{2} \sqrt{ } P$} & \multicolumn{9}{|c|}{ Short-distance interrogation of the optical cable $(<500 \mathrm{~m})$} \\
\hline & & & $\begin{array}{c}\text { Pass } \\
\text { A } \\
(\%)\end{array}$ & $\begin{array}{c}\text { Pass } \\
\text { B } \\
(\%)\end{array}$ & $\begin{array}{c}\text { Pass } \\
\text { C } \\
(\%)\end{array}$ & $\begin{array}{c}\text { Pass } \\
\text { D } \\
(\%)\end{array}$ & $\begin{array}{c}\text { Pass } \\
\text { E } \\
(\%)\end{array}$ & $\begin{array}{c}\text { Pass } \\
\mathrm{F} \\
(\%)\end{array}$ & $\begin{array}{c}\text { Pass } \\
\text { G } \\
(\%)\end{array}$ & $\begin{array}{c}\text { Pass } \\
\mathrm{H} \\
(\%)\end{array}$ & $\begin{array}{c}\text { Pass } \\
\text { I } \\
(\%)\end{array}$ \\
\hline Test 13 & $\begin{array}{l}7 \mathrm{~mm}, 77 \\
\text { bar, up }\end{array}$ & 430,0 & 100 & 25 & 0 & 100 & 100 & 100 & 100 & 75 & 0 \\
\hline Test 2 & $\begin{array}{l}7 \mathrm{~mm}, 48 \\
\text { bar, down }\end{array}$ & 339,5 & 25 & 25 & 0 & 100 & 100 & 75 & 100 & 100 & 100 \\
\hline Test 8 & $\begin{array}{l}7 \mathrm{~mm}, 44 \\
\text { bar, side }\end{array}$ & 325,0 & 0 & 0 & 0 & 25 & 50 & 75 & 75 & 100 & 100 \\
\hline Test 5 & $\begin{array}{l}7 \mathrm{~mm}, 20 \\
\text { bar, down }\end{array}$ & 219,1 & 25 & 0 & 0 & 25 & 25 & 25 & 25 & 100 & 100 \\
\hline Test 19 & $\begin{array}{l}7 \mathrm{~mm}, 20 \\
\text { bar, up }\end{array}$ & 207,9 & 25 & 0 & 0 & 0 & 100 & 100 & 100 & 75 & NA \\
\hline Test 11 & $\begin{array}{l}3 \mathrm{~mm}, 87 \\
\text { bar, side }\end{array}$ & 83,9 & 0 & 0 & 0 & 0 & 25 & 25 & 0 & 100 & 25 \\
\hline Test 9 & $\begin{array}{l}3 \mathrm{~mm}, 79 \\
\text { bar, down }\end{array}$ & 80,0 & 25 & 25 & 25 & 0 & 50 & 0 & 0 & 100 & 25 \\
\hline Test 4 & $\begin{array}{l}3 \mathrm{~mm}, 77 \\
\text { bar, up }\end{array}$ & 79,0 & 0 & 0 & 0 & 100 & 100 & 100 & 100 & 75 & 0 \\
\hline
\end{tabular}




\begin{tabular}{|c|c|c|c|c|c|c|c|c|c|c|c|}
\hline & & \multirow[b]{2}{*}{$D^{2} \sqrt{ } P$} & \multicolumn{9}{|c|}{ Short-distance interrogation of the optical cable $(<500 \mathrm{~m})$} \\
\hline & & & $\begin{array}{c}\text { Pass } \\
\text { A } \\
(\%)\end{array}$ & $\begin{array}{c}\text { Pass } \\
\text { B } \\
(\%)\end{array}$ & $\begin{array}{c}\text { Pass } \\
\text { C } \\
(\%)\end{array}$ & $\begin{array}{c}\text { Pass } \\
\text { D } \\
(\%)\end{array}$ & $\begin{array}{c}\text { Pass } \\
\text { E } \\
(\%)\end{array}$ & $\begin{array}{c}\text { Pass } \\
\text { F } \\
(\%)\end{array}$ & $\begin{array}{c}\text { Pass } \\
\text { G } \\
(\%)\end{array}$ & $\begin{array}{c}\text { Pass } \\
\mathrm{H} \\
(\%)\end{array}$ & $\begin{array}{c}\text { Pass } \\
\text { I } \\
(\%)\end{array}$ \\
\hline Test 15 & $\begin{array}{l}3 \mathrm{~mm}, 40 \\
\text { bar, up }\end{array}$ & 56,9 & 0 & 0 & 0 & 0 & 75 & 100 & 100 & 50 & NA \\
\hline Test 16 & $\begin{array}{l}3 \mathrm{~mm}, 39 \\
\text { bar, side }\end{array}$ & 56,2 & 0 & 0 & 0 & 0 & 0 & 0 & 0 & 100 & NA \\
\hline Test 10 & $\begin{array}{l}3 \mathrm{~mm}, 19 \\
\text { bar, down }\end{array}$ & 39,2 & 0 & 0 & 0 & 0 & 0 & 0 & 0 & 75 & 25 \\
\hline Test 12 & $\begin{array}{l}3 \mathrm{~mm}, 16 \\
\text { bar, side }\end{array}$ & 36,0 & 0 & 0 & 0 & 0 & 0 & 0 & 0 & 25 & 0 \\
\hline Test 7 & $\begin{array}{l}1 \mathrm{~mm}, 111 \\
\text { bar, side }\end{array}$ & 10,6 & 0 & 0 & 0 & 0 & 0 & 0 & 0 & 100 & 0 \\
\hline Test 6 & $\begin{array}{l}1 \mathrm{~mm}, 111 \\
\text { bar, down }\end{array}$ & 10,5 & 0 & 0 & 0 & 0 & 0 & 0 & 0 & 0 & 0 \\
\hline Test 20 & $\begin{array}{l}1 \mathrm{~mm}, 99 \\
\text { bar, down }\end{array}$ & 9,9 & 0 & 0 & 0 & 25 & 100 & 25 & 25 & 100 & NA \\
\hline Test 1 & $\begin{array}{l}1 \mathrm{~mm}, 81 \\
\text { bar, up }\end{array}$ & 9,0 & 0 & 0 & 0 & 0 & 33 & 0 & 0 & 100 & 0 \\
\hline Test 3 & $\begin{array}{l}1 \mathrm{~mm}, 23 \\
\text { bar, up }\end{array}$ & 4,8 & 0 & 0 & 0 & 0 & 0 & 0 & 0 & 0 & 0 \\
\hline
\end{tabular}

- Pass $\mathrm{H}$ was the most efficient to trigger alerts on the simulated leaks. One should recall that the buried pipe was uncoated during the FOLD testing campaign. In addition, the gas was not necessarily at ambient temperature in the vicinity of the nozzle orifice since it was expanded to the desired released pressure prior to leaking. Taking these two considerations into account, the behaviour of Pass $\mathrm{H}$ may have been dominated by the conduction effect taking place along the metal rather by the Joule-Thomson effect caused by the leak itself.

- It seems preferable to locate the optical cable above the pipe, not more than $20 \mathrm{~cm}$ from it. This recommendation is motivated by the behaviour of Pass E, which was quite successful to detect leaks having $D^{2} \sqrt{ } P$ greater than $80-100$, whatever the release direction. From Table 4 it can be seen that this preferred location could also be efficient in case of an upward leak even if the release orifice is as small as $1 \mathrm{~mm}$.

\section{CONCLUSIONS}

Within the frame of the FOLD project, an experimental bench was built to assess the efficiency of a fibre optic based system to detect a gaseous leak on a buried pipe. Only part of the experimental results has been analysed up to now.

The analysis of the results obtained by interrogating $500 \mathrm{~m}$ of the optical cable using DTS apparatus showed that it might be possible to detect leaks of methane that lasted for not more than 15 min provided that the cable is located above the buried pipe and with an offset not exceeding $20 \mathrm{~cm}$. 
Listed below is some of the work that will be carried out by the FOLD partnership over the coming months:

- To assess the influence of the optical cable length on the detection performance

- To perform a critical analysis of the DTS conclusions provided by the suppliers

- To analyse the acoustic data generated by the DAS apparatus during the testing campaign and to compare the performance of DAS vs DTS

\section{REFERENCES}

[1] EGIG, « Gas Pipeline Incidents - 9th report of the European gas pipeline incident data group (period 1970 - 2013) », Doc n¹4.R.0403, février 2015. 